second opinion supportive in the difficult decisions they have to make. Even those initially reluctant have started to find that the new system looks after the interests of patient and doctor alike. Any system can be made to fail by those determined on failure. The Commission's perception is that the opposite is occurring and we welcome and seek to advance this constructive response.

The question, of course, arises under all provisions in the Act for a second opinion: who is and remains responsible for the patient? The answer is the doctor in charge of the patient's treatment, who, for detained patients, is the RMO. The second opinion is not imposed on him; it is not an insistence by the second opinion doctor on treatment which he would have chosen to give if the primary decision had been his own. Perhaps, in a difficult area of medicine, Parliament has seen fit to attempt a reinforcement of the RMO's clinical opinion, or room for professional discussion. Many doctors now view it thus. I find it impossible, therefore, to extract from that overall pattern, involving standard treatments for mental disorder, the comparatively rare case of psychosurgery. The idea of a medical second opinion there implies no different approach. What the Act adds is another stage, since the operation is irreversible. The two non-medical Commissioners join their doctor colleague in confirming the vital question of the patient's consent. Dr Bridges' article asserts that in some cases there certainly can be doubt on this point. We agree; and would add that the task is not made any easier if access to the patient's notes is denied.

It comes to this. The 1983 Act requires second opinions for a variety of treatments. In every case there is, in theory, a power of veto. In every case there is, in practice, a chance for the hospital staff concerned to seek confirmation of their own judgement from an independent source. The second is the positive approach. Dr Bridges, however, seems to look upon the scheme of the Act as one which threatens the professional opinion and advice of a whole range of experts. Then, in his addendum (Bulletin, September $1984,8,172$ ), he brings in the suicide. That is indeed an emotive matter. I hardly think it necessary to say that the Commission would earnestly seek to avoid any decision which leads a patient to suicide. Yet there is a risk in many cases of mental illness. Possibly some consultants have never suffered such an outcome in their patient; just possibly some have never known about it. The danger must not affect and has not affected in the past the application of bona fide professional judgement.

I am here in a difficulty. All professional people are aware of that absolute quality of confidentiality for any client's case. My legal background ensures that the rule shall be maintained. Thus I cannot discuss in public the decision reached in respect of any individual patient, nor the reasons for it, fully though I have investigated it. Nor am I prepared to comment on the professional skills of anyone called upon to give a second opinion under Sections $\mathbf{5 7}$ or $\mathbf{5 8}$. I must be content with saying that I find it hard to accept that with all the advice available to him the Secretary of State was so inept in his appointments; that he chose doctor Commissioners not one of whom is fit to carry out the task imposed by the Act, even in psychosurgery cases; that not one of them is qualified to discuss with the RMO the alternatives available in the unusual case of a disagreement.

The situation may be different in Scotland and North America. Within the last few years Parliament debated at length, for England and Wales, all the controversial questions raised in Dr Bridges' article. The fact must be faced that it was decided on behalf of society to impose a check on certain matters of medical discretion. It is his right to disagree with those decisions and in a recent letter I have told him that the Commission respects him no less on that account. He will doubtless pursue the matter in the correct forum at Westminster. The Commission, however, was created by the same legislation. It is set up, among other things, to make the new system work. I have tried to describe how it seeks to do so. I do not think that the Commission membership is inadequate, or that its procedures are faulty. As to procedures, there is always room for further thought, but I am puzzled by Dr Bridges' suggestion, at the end of the article, of a new system at his Unit. We agree with him that the current method, devised with his co-operation, is working quite well.

The innovations in the 1983 Act may not be popular in every quarter. There is, however, little latitude in the duties laid on the Commission as regards second opinions. Within the limits of our discretion it is intended to continue identifying and seeking to solve the practical problems as they emerge.

\title{
Revised regulations for the MRCPI
}

The Royal College of Physicians of Ireland, at its Annual Stated Meeting on 18 October 1984, agreed to include the MRCPsych under the qualifications agreed for exemption from MRCPI Part I, under its Bye-Law 18. This means that those who hold the MRCPsych may proceed directly to MRCPI Part II, which, as is probably known, may be taken in the special subject of psychiatry.
The format is clinical, written and oral examinations in psychiatry, and clinical and oral examinations in general medicine, with special reference to neurology and psychiatry.

It is hoped that this move may enable psychiatrists to continue to exert influence within one of the major academic bodies in medicine in Ireland. 